\title{
Production of Bioethanol from Dragon Fruit Wastes by Using Aspergillus niger and Saccharomycetes cerevisae
}

\author{
Selvia Sarungu ${ }^{1}$, Karnila Willard², Hamriani Ryka ${ }^{3}$, Simon Tampang ${ }^{1}$, Junaesar \\ Tangke Tasik ${ }^{1}$, Bodhi Dharma ${ }^{4}$, Sitompul Afrida ${ }^{2, *}$ \\ ${ }^{1}$ Department of Industrial Engineering, STT Migas, Balikpapan, East Kalimantan, 76127, Indonesia \\ ${ }^{2}$ Department of Petroleum Engineering, STT Migas, Balikpapan, East Kalimantan, 76127, Indonesia \\ ${ }^{3}$ Department of Geological Engineering, STT Migas, Balikpapan, East Kalimantan, 76127, Indonesia \\ ${ }^{4}$ Department of Biology, Faculty of Mathematics and Natural Sciences,Mulawarman University, East Kalimantan, \\ 75123, Indonesia \\ *Corresponding author. Email: afrida.sitompul0214@gmail.com
}

\begin{abstract}
East Kalimantan are able to produce dragon fruit throughout year, while, East Java are only in raining season. This fruit will be produced abundantly when the peak season comes and often becomes waste. To reduce this cellulosic waste from traditional market, we attempt to convert the dragon fruit waste become bioethanol. In this study, the ability of cocultures (A. niger and S. cerevisiae) and mono-culture (only S. cerevisiae) to produce bioethanol was evaluated. The red dragon fruit waste was treated with simultaneously saccharification and fermentation by using Aspergillus niger and Saccharomyces cerevisiae showed the highest concentration of alcohol was $48.0 \%$ after 3 weeks incubation. Subsequently, the use only $S$. cerevisiae to produce bioethanol was found to be able to produce $64.5 \%$ alcohol concentration after 2 weeks incubation. The highest concentration of alcohol was showed when the concentration of $S$. cerevisiae was $0.67 \%$. These observations confirm that mono-culture has higher alcohol concentration compared to cocultures treatment.
\end{abstract}

Keywords: Mono-culture, Co-cultures, Saccharification, Fermentation, Second generation of bioethanol

\section{INTRODUCTION}

Cultivation of dragon fruit has introduced in Indonesia since 1997 and developed fast in 2000. The main cultivated areas are Sumatra, Java, Kalimantan, and Sulawesi [1]. East Kalimantan is one of the productive area on dragon fruit cultivating because can flowering and fruiting throughout the year with area $1500 \mathrm{Ha}$ and yield productivity is 22-28 ton/Ha/year [2]. The good grade of dragon fruit can be stored for 7 days at room temperature, unless it stores at cold storage. Low-grade fruit is often found on traditional market due to ripen and rotten which is not consumed by human and generally discharged as a waste. To make value-added product in feasible way, the fruit waste is using as feedstock for bioethanol production [3].

Ethanol is a suitable biofuel to substitute fossil fuel or to be additive to gasoline [4,5]. Ethanol is widely produced from starchy biomass or sucrose such as sugarcane, corn, and potato [6]. However, it triggers competition between fuel and food. Alternatively, to avoid the competition in ethanol production, second generation of biomass is being developed such as lignocellulosic biomass [7,8]. Fruit waste is inexpensive lignocellulosic biomass and promising feedstock for ethanol production because they are available abundantly; particularly in tropical country where the fruits are produced throughout the year. Fruit wastes (mostly seeds and peels) are generated from conversion of the food processing. However, low-grade fruit is also can be consider as a fruit waste.

Red-flesh dragon fruit contains $401 \mathrm{~g} / \mathrm{kg}$ of glucose, $89.6 \mathrm{~g} / \mathrm{kg}$ of oligosaccharides, and $0.32 \mathrm{~g} / \mathrm{kg}$ of fructose [9]. According to Brunerová et al. [10] that dragon fruit waste biomass was $36.94 \%$ and $\mathrm{C}: \mathrm{N}$ ratio observed was 21.15. Hence, it shows that dragon fruit has proper condition to decompose of compost component. These chemical components of dragon fruit are suitable for ethanol production. 
Pre-treatment of fruit waste for bioethanol production is needed to get success of gaining bioethanol, particularly for fruit containing high cellulose. There are several methods that can be used to degrade cellulose into sugars such enzyme, acid or alkaline, autoclaving, microwave heating and ultra sonication [11,12]. Recently, scientist has much attention to combine fungus which has enzyme to hydrolyze cellulose into sugar such as Aspergilus niger or Trichoderma reesei and Saccharomyces cerevisiae [13,14]. Moreover, study of simultaneous saccharification and fermentation using $A$. niger and $S$. cerevisiae has been reported [14-17]; the results showed that using co-coltures increased several fold of ethanol yield compared to mono-culture.

Here, we study the red dragon fruit wastes for bioethanol production. The aim of this study was to examine the ability co-cultures (A. niger and $S$. cerevisiae) and mono-culture (only $S$. cerevisiae) to produce bioethanol. In this study, we also evaluated the effect of concentration of $S$. cerevisiae in bioethanol production.

\section{MATERIALS AND METHOD}

\subsection{Raw Materials and Microorganisms}

Low-grade and ripen red dragon fruit are used in this study. These fruits were bought from one of traditional markets in Balikpapan, East Kalimantan. The raw materials were manually cleaned and immediately prepared for determining water content and for substrate preparations.

The fungus of $A$. niger was a kind gift from Dr. Bodhi Darma from Mulawarman University. The fungus was maintained on potato dextrose agar (PDA, Himedia, India) slants and sub-cultured on petri dish containing PDA at room temperature $\left(28-30^{\circ} \mathrm{C}\right)$ for 7 days. Meanwhile, S. cerevisiae was used commercial baker's yeast with brand Fermipan (Lesaffere, France and imported by PT. Sangra Ratu Boga). It was bought from traditional market.

\subsection{Inocula Preparation}

The A. niger inoculum was prepared using potato dextrose broth (PDB) as described by Sarungu et al. [18]. The medium contained $400 \mathrm{~g}$ of potato, $15 \mathrm{~g}$ of dextrose (Himedia, India), and $1000 \mathrm{ml}$ of water. The potato was cut into pieces $(2 \mathrm{~cm} \times 2 \mathrm{~cm})$, added water, cooked to a boil and allowed for 1 hour with the small flame, and then filtered the broth and added dextrose. The medium was sterilized for $15 \mathrm{~min}$ at $121^{\circ} \mathrm{C}$. After cooling, the PDB medium was inoculated with three plugs of A. niger (1 $\mathrm{cm} \times 1 \mathrm{~cm}$ ) from 1-week-old culture grown on PDA and incubated at room temperature for 10 days. Subsequently, the cultures were blended using juice blender before used the blender was sprayed with $70 \%$ ethanol and wiped with clean tissues.

The $S$. cerevisiae (yeast) inoculum was prepared in $1000-\mathrm{ml}$ beaker glass. Forty grams of sugar were placed into beaker glass and added $400 \mathrm{ml}$ of distilled water, covered with aluminium foil, and sterilized using autoclave for $15 \mathrm{~min}$ at $121^{\circ} \mathrm{C}$. After cooling, added $20 \mathrm{~g}$ of yeast and incubated for 8 hours at room temperature $\left(26 \pm 2{ }^{\circ} \mathrm{C}\right)$. The inoculum was used for all the carried out experiment.

\subsection{Substrate Preparation}

The low-grade red dragon fruits were cut into small pieces and take around two grams for determining water content. The samples were dried in an oven at $105^{\circ} \mathrm{C}$ for 24 hours and then weighted to a constant mass.

For making substrate on bioethanol production, small pieces of dragon fruits were added into 1000-ml graduated cylinder glass which contained $500 \mathrm{ml}$ distilled water until reached the gauge sign on the glass $(1: 1)$. Afterward, blended the fruits until becoming pulp with using juice blender. Then, the pulp was added $240 \mathrm{ml}$ into 500-ml Erlenmeyer flask, supplemented with $0.18 \mathrm{~g}$ of urea, and $0.11 \mathrm{~g}$ of nitrogen, phosphorus, and potassium (NPK). All the flasks were closely tightened with aluminium foil and set into autoclave at $121^{\circ} \mathrm{C}$ for 15 min. Theses substrates were used for next experiment.

\subsection{Bioethanol Production}

The Erlenmeyer flasks containing substrates were aseptically added with $30 \mathrm{ml}(10 \% \mathrm{v} / \mathrm{v})$ of $A$. niger and $30 \mathrm{ml}(10 \% \mathrm{v} / \mathrm{v})$ of $S$. cerevisiae. All the flasks were incubated in the static condition at room temperature for 28 days. The alcohol concentration produced was observed every 7 days.

In this study, the production of bioethanol from red dragon fruit wastes without addition of $A$. niger was evaluated. To 500-ml Erlenmeyer flask was added 270 $\mathrm{ml}$ of fruit pulp, $0.18 \mathrm{~g}$ of urea, $0.11 \mathrm{~g}$ of NPK, and was sterilized. After cooling, the substrates were added with $30 \mathrm{ml}(10 \% \mathrm{v} / \mathrm{v})$ of S. cerevisiae and fermented statically at room temperature for 28 days. Every 7 days were analysis for alcohol concentration.

\subsection{Effect of S. cerevisiae on Bioethanol Production}

Concentration of $S$. cerevisiae plays important role in the production of bioethanol. To optimize the concentration of $\mathrm{S}$. cerevisiae, fermentation was carried out at room temperature with varying concentration from $10 \mathrm{ml}(3.33 \% \mathrm{v} / \mathrm{v})$ to $60 \mathrm{ml}(20.00 \% \mathrm{v} / \mathrm{v})$ and incubated for 14 days. 
All the experiments in this study were performed in triplicate.

\subsection{Analytical Procedures}

The cultures from each Erlenmeyer flask was poured into 500-ml distillation flask. Distillation apparatus was used and set the heating mantle plate (98-II-B Magnetic Stirring Electric Sleeve) temperature at $70-78{ }^{\circ} \mathrm{C}$. The distillation process was carried out for 2 hours.

Bioethanol concentration was determined by using a standard curve of density against percentage ethanol. Density of each ethanol solution prepared was calculated by weight of each mass of ethanol solution in 10-ml Pycnometer divided with its volume.

\section{RESULTS AND DISCUSSION}

Fruit waste is good feedstock for bioethanol production because it is not consume and cheap. The dragon fruit waste was used in this study contained water $88,4 \%$ and $90.2 \%$ for pericarp and flesh, respectively. We used whole dragon fruit waste to produce bioethanol.

Figure 1 showed that treatment dragon fruit wastes using co-culture A. niger and S. cerevisiae in the liquid medium revealed highest concentration after incubation for 3 weeks $(48.0 \%)$. This method referred to as simultaneous saccharification and fermentation, where the breakdown of complex sugars into simple sugars and followed by the conversion of simple sugars into ethanol in one container. However, when the only S. cerevisiae was added in the medium to ferment dragon fruit waste, the concentration of bioethanol was higher gained compared to co-culture A. niger and S. cerevisiae. Two weeks incubation by using only $S$. cerevisiae produced $64.5 \%$ of bioethanol. The results gained in this study was contradicted with research was done by Ohta et al. [16] where they found using mycelium-containing culture was higher in bioethanol concentration compared to mycelium-free culture. It seems that in our study containing culture of $A$. niger inhibited performance of $S$. cerevisiae. The similar results we have found when mango fruit wastes was treated with A. niger and $S$. cerevisiae [18]. This is probably because the concentration of $S$. cerevisiae used in this study was too low $(0.50 \% \mathrm{v} / \mathrm{v})$. Abouzied and Reddy [15] have reported that the concentration of $S$. cerevisiae used during simultaneous saccharification and fermentation was 5\% $\mathrm{v} / \mathrm{v}$. Furthermore, they found that increasing the level of S. cerevisiae $(12 \% \mathrm{w} / \mathrm{v})$ used greatly decreases the fermentation time. Therefore, further research in the current study is needed to understand the effect mycelium-containing co-culture of $A$. niger and $S$. cerevisiae in bioethanol production.

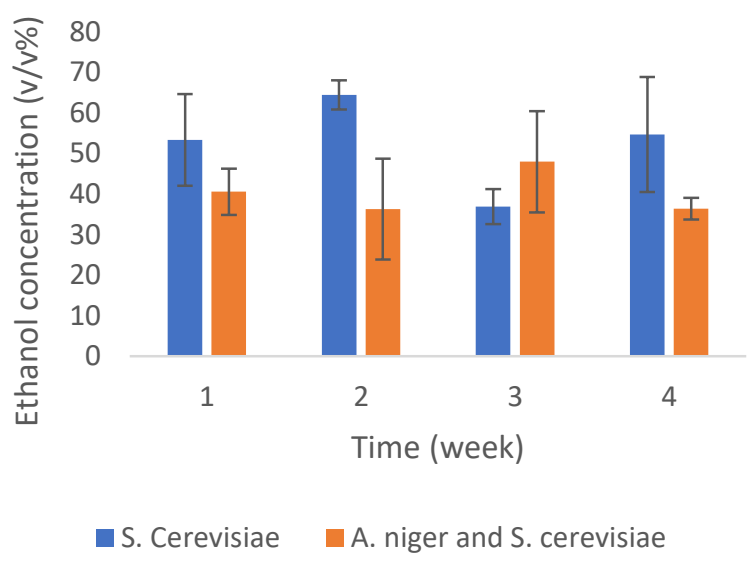

Figure 1 Comparison of bioethanol concentration produced after fermented for four weeks by co-culture ( $A$. niger and S. cerevisiae) and mono-culture (S. cerevisiae) using red dragon fruit waste as substrate

Table 1. Effect of concentration of S. cerevisiae to concentration of bioethanol produced after fermented for 14 days.

\begin{tabular}{c|c|c}
\hline $\begin{array}{c}\text { Volume of culture } \\
\text { of } \text { S. cereviceae } \\
\text { added }(\mathrm{mL})\end{array}$ & $\begin{array}{c}\text { S. cerevisiae } \\
\text { concentration } \\
(\% \mathrm{v} / \mathrm{v})\end{array}$ & $\begin{array}{c}\text { Bioethanol } \\
\text { concentration } \\
(\% \mathrm{v} / \mathrm{v})\end{array}$ \\
\hline 10 & 0.17 & $39.3 \pm 15.7$ \\
\hline 20 & 0.33 & $51.3 \pm 5.3$ \\
\hline 30 & 0.50 & $56.0 \pm 11.4$ \\
\hline 40 & 0.67 & $60.2 \pm 23.0$ \\
\hline 50 & 0.83 & $46.7 \pm 11.6$ \\
\hline 60 & 1.00 & $54.8 \pm 18.2$ \\
\hline
\end{tabular}

Most studies use simultaneous saccharification and fermentation method conducted in the mycelium-free culture using extracellular enzymes produced by $A$. niger to hydrolyse complex sugars $[17 ; 7 ; 14]$.

Next, the optimum concentration of $S$. cerevisiae to produce bioethanol in the liquid culture was $0,67 \%$ and concentration of the bioethanol produced was $60.2 \%$. However, the concentration of S. cerevisiae used in current study was low compared to Abouzied and Reddy [15].

The heating mantle that we used in study was difficult to maintain on desired temperature $\left(78^{\circ} \mathrm{C}\right)$. The heating mantle temperature fluctuated from 70 to $78{ }^{\circ} \mathrm{C}$. We suggest it may affect the yield concentration of bioethanol.

\section{CONCLUSION}

Mono-culture using $S$. cerevisiae to produce bioethanol showed higher in concentration (64.5\%) compared to co-culture A. niger and $S$. cerevisiae 
(48.0\%). The optimum concentration of S. cerevisiae was $0.67 \%$. From this study dragon fruit wastes could be potential feedstock to produce bioethanol.

\section{ACKNOWLEDGMENTS}

We thank to STT Migas for financial support so this research was able to run.

\section{REFERENCES}

[1] Muas I, Jumjunidang. Status dragon fruit cultivation and marketing in Indonesia. Improving Pitaya Production and Marketing. 2015:19-29. https://www.fftc.org.tw/htmlarea_file/activities/201 50817121105/02-15P10.pdf.

[2] Mansyah E, Hendri, Muas I, Yuliati S. Dragon fruit in Indonesia: Standard quality in the global and regional levels. Overview of Agricultural Policy. 2019. https://ap.fftc.org.tw/article/1601.

[3] Kim S, Dale BE. Global potential bioethanol production from wasted crops and crop residues. Biomass \& Bioenergy. 2004;26:361-375.

[4] Wyman C. Biomass ethanol: technical progress, opportunities, and commercial challenges. In: Socolow R, Anderson D, Harte J (Eds). Annual Review of Energy Environmental. 1999; 24:189226.

[5] Kelbert M, Romaní A, Coelho E, Pereira FB, Teixeira JA, Domingues L. Simultaneous saccharification and fermentation of hydrothermal pretreated lignocellulosic biomass: evaluation of process performance under multiple stress conditions. BioEnergy Research. 2016;9:750-762. http://dx.doi.org/10.1007/s12155-016-9722-6.

[6] Sargar N, Kolhe V, Nale M. Experimental Synthesis of Ethanol from Sugarcan Juice Molasses. Galore International Journal of Applied Sciences and Humanities. 2017;1(1):48-52.

[7] Sukumaran RK, Singhania RR, Mathew GM, Pandey A. Cellulase production using biomass feed stock and its application in lignocellulose saccharification for bio-ethanol production. Renewable Energy. 2009;34:421-424.

[8] Guerrero AB, Ballesteros I, Ballesteros M. The potential of agricultural banana waste for bioethanol production. Fuel. 2018;213:176-185.

[9] Wichienchot S, Jatupornpipat M, Rastall RA. Oligosaccharides of pitaya (dragon fruit) flesh and their probiotics properties. Food Chemistry. 2010;3(1): 850-857.
[10] Brunerová A, Hasanudin U, Iryani DA, Herák. Analysis of tropical fruit waste biomass generation in Indonesia and its reuse potential. Advances in Engineering Research. Proceeding of the Interational Conference on Sustainable Biomass. 2019; 202:158-163.

[11] Widmer W, Zhou W, Grohmann K. Pretreatment effects on orange processing waste for making ethanol by simultaneous saccharification and fermentation. Bioresource Technology. 2010;101:5242-5249.

[12] Gabhane J, William SPMP, Gadhe A, Rath R, Vaidya AN, Wate S. Pretreatment of banana agricultural waste for bio-ethanol production: Individual and interactive effects of acid and alkali pretreatments with autoclaving, microwave heating and ultrasonication. Waste Management. 2014;34:498-503.

[13] Chamchoi N. Utilization of fruit waste for bioethanol production by co-culture of Aspergillus niger and Saccharomycete cerevisiae. Applied Environmental Research. 2019;41(2):63-72.

[14] Widyaningrum T, Parahadi M. Bioethanol level of dragon fruit (Hylocereus polyrhizus) peel with the addition of bled crude cellulase enzyme from Tricodherma reesei and Aspergillus niger. Journal of Tropical Biodiversity and Bioetchnology. 2020; 5(1): $1-5$.

[15] Abouzied MM, Reddy A. Direct fermentation of potato starch to ethanol by cocultures of Aspergillus niger and Saccharomycetes cerevisiae. Applied and Environmental Microbiology. 1986;52:1055-1059.

[16] Ohta K, Hamada S, Nakamura T. Production of high concentration of ethanol from inulin by simultaneous saccharification and fermentation using Aspergillus niger and Saccharomyces cerevisiae. Applied And Environmental Microbiology. 1993;59:729-733.

[17] Zakpaa HD, Mak-Mensah EE, Johnson FS. Production of bioethanol from corncobs using Aspergillus niger and Saccharomycetes cerevisae in simultaneous saccharification and fermentation. African Journal of Biotechnology. 2009;8:30183022 .

[18] Sarungu S, Afrida S, Lumbaa M. Utilization of mango waste for bioethanol production using Aspergillus niger and Saccharomycetes cerevisae: A pilot-scale study. Petrogas. 2021;3(1): 27-34. 